trainees who have not been allocated a psychiatry job. We have found that acute hospital clinicians value the training provided by liaison psychiatry teams to trainee doctors. ${ }^{5}$ Liaison psychiatrists are thus uniquely placed to take on foundation year trainees and be the gateway to psychiatry for an increasing number of trainees.

1 Welch J, Bridge C, Firth D, Forrest A. Improving psychiatry training in the Foundation Programme. Psychiatrist 2011; 35: 389-93.

2 Tallentire V, Smith S, Wylde K, Cameron H. Are medical graduates ready to face the challenges of Foundation training? Postgrad Med J 2011; 87: 590-5.

3 Maidment R, Livingston G, Katona C, McParland M, Noble L. Change in attitudes to psychiatry and intention to pursue psychiatry as a career in newly qualified doctors: a follow-up of two cohorts of medical students. Med Teach 2004; 26: 565-9.

4 Boyle AM, Chaloner DA, Millward T, Rao V, Messer C. Recruitment from foundation year 2 posts into specialty training: a potential success story? Psychiatr Bull 2009; 33: 306-8

5 Solomons L, Thachil A, Burgess C, Glen-Day V, Hopper A, Ranjith G, et al. Quality of psychiatric care in the general hospital: referrer perceptions of an inpatient liaison psychiatry service. Gen Hosp Psychiatry 2011; 33: 260-6.

Luke Solomons, consultant liaison psychiatrist, Berkshire Healthcare NHS Foundation Trust, Royal Berkshire Hospital, Reading, UK, email: luke.solomons@berkshire.nhs.uk; Gopinath Ranjith, consultant liaison psychiatrist, Guy's and St Thomas' NHS Foundation Trust, St Thomas' Hospital, London, UK.

doi: $10.1192 / \mathrm{pb} .36 .1 .35 \mathrm{a}$

\section{Minority report on violence risk assessment}

The cover of the July 2011 issue of The Psychiatrist featured the unshaven face of a young man staring impassively back at the reader, with the caption 'Psychiatric Report', in what was an unmistakable parody of the publicity posters for Steven Spielberg's science-fiction neo-noir classic, Minority Report. The cover referred to two articles within about psychiatric report writing. We see similarities between the central idea of the film and those psychiatric reports that claim to estimate the risk of future violence.

Based on a short story by Philip K. Dick, Minority Report took us to Washington DC in 2054, a world where homicides can be prevented. A special police department, the Pre-Crime Unit, apprehends people before they commit a murder, based on the reports of three psychic 'pre-cogs'. Once identified by the pre-cogs, criminals-to-be are apprehended and permanently placed into a state of suspended animation. The story follows the plight of John Anderton, played by Tom Cruise, who discovers that he is about to be arrested for a murder he is sure he will never commit. The movie works because we empathise with Anderton as he realises the injustice of convicting people who have yet to commit a crime and struggles against both the particular error in prediction and sinister political opportunism based on fear of crime.

The Mental Health Act demands the detention of a person with a mental disorder if 'he ought to be so detained in the interests of his own health or safety or with a view to the protection of other persons [emphasis mine]' (Part II, Section 2 (2b)). Unfortunately, current psychiatric risk assessment, on which decisions to protect the public might be made, compare very poorly with the powers of the fictional pre-cogs.
In the most optimal circumstances, using the best instruments, a sensitivity and specificity of $80 \%$ might just be achieved. ${ }^{1}$ If Pre-Crime had used risk assessment with this predictive power in the years before 2054, about 200 murders would still have occurred, 800 would have been prevented and 20000 citizens of Washington DC (2\% of the population) would have been needlessly frozen. In the film, Pre-Crime is eventually shut down, because even a single false positive is unacceptable to the Washingtonians of the future. Back in the real world, the Mental Health Act continues to demand that doctors make judgements about detention for the protection of others.

The false positive rate is a major problem with violence risk assessment in psychiatry and for mental health legislation that requires judgements about future harm. False positives waste resources, and lead to needless and unfair detention and excessive treatment. ${ }^{2}$ True negatives can also be a problem if mental health law does not allow the treatment of those who cannot consent to it by virtue of incapacity, but who are not judged a threat to themselves or others. ${ }^{3}$

Moreover, there is no evidence that the application of risk assessment can offer adequate protection to the public. ${ }^{4}$ Risk assessment, as it is currently practised in psychiatry, is so flawed that it should not be used as the basis for clinical decision-making or coercive treatment. Instead, treatment decisions should be made as they are in the rest of medicine, after discussing the risks and benefits of treatment with the patient or, in the case of those who lack capacity, be made in the patient's best interests, after discussion with a proxy decision maker.

1 Large MM, Ryan CJ, Paton M, Nielssen O, Singh S. The predictive value of risk categorization in schizophrenia. Harv Rev Psychiatry 2011; 19: 25-33.

2 Nielssen O, Ryan C, Large M. Risk assessment and resource allocation. Australas Psychiatry 2011; 19: 270.

3 Large MM, Ryan CJ, Nielssen OB, Hayes RA. The danger of dangerousness: why we must remove the dangerousness criterion from our mental health acts. J Med Ethics 2008; 34: 877-81.

4 Mossman D. The imperfection of protection through detection and intervention. Lessons from three decades of research on the psychiatric assessment of violence risk. J Leg Med 2009; 30: 109-40.

5 Ryan CJ, Nielssen O, Paton MB, Large M. Clinical decisions in psychiatry should not be based on risk-assessment. Australas Psychiatry 2010; 18: $398-403$

Matthew Large, Psychiatrist, The Prince of Wales Hospital, and Conjoint Senior Lecturer, School of Psychiatry, University of New South Wales, Sydney, Australia, email: mmbl@bigpond.com; Christopher Ryan, Consultation-Liaison Psychiatrist, Westmead Hospital, and Clinical Senior Lecturer, Centre for Values, Ethics and the Law in Medicine, University of Sydney, Australia; Olav Nielssen, Psychiatrist, St Vincent's Hospital, and Conjoint Senior Lecturer, Clinical Research Unit for Anxiety and Depression, School of Psychiatry, University of New South Wales, Sydney, Australia.

doi: $10.1192 / p b .36 .1 .36$

\section{Adult attention-deficit hyperactivity disorder - a very much real diagnosis}

Moncrieff \& Timimi $^{1}$ have challenged whether adult attentiondeficit hyperactivity disorder (ADHD) exists as a discrete condition. They suggest that it is merely the medicalisiation of ordinary human difficulties and that the diagnosis is being pushed by pharmaceutical companies who then make a tidy 